\title{
Visa veto worries dissidents
}

\section{Washington}

REACTION among students from mainland China in the United States ranged from indignation to cautious optimism last week after Congress failed by four votes to overturn President George Bush's veto of a bill that would have allowed the students to stay in the United States - and avoid possible punishment on their return to China - for up to four years after their visas had expired.

The President argued that allowing the bill to become law would have further strained relations between the two countries and left the United States with far less leverage in ensuring China's compliance on human rights. In place of the vetoed legislation, Bush has promised to issue an executive order that would serve as a functional equivalent. This, he says, will be perceived as less antagonistic by the Chinese government. But some Chinese students say that they do not trust the administration to keep its word.

Yuan Liu of the Massachusetts-based China Information Center "fears for the future" of Chinese students in the United States, with nothing but the President's executive order protecting them from deportation. He says that the administration's actions in past months - two secret trips by top-level administration officials to meet with Chinese leaders, and a partial lifting of trade embargoes - have left the students with "a lack of confidence" in the administration's policy un China.

Liu argues that the only reason Chinese leaders may be less offended by an executive order, rather than congressional legislation, is that they recognize that an order can be lifted at will whereas a law can be removed only by an act of Congress.

Chinese students worry that policy could be reversed at some point in the future to appease China, he says. "The majority of students here would like to go back some time, but now is a bad time." Most Chinese students in the United States fear they will be labelled as dissidents if they return to China, Liu says.

Others in the US Chinese population greeted Bush's promise with more approval. "A law reflects some kind of permanency. But with China we're dealing with a changing situation", says one Chinese-American university professor. Bush stated last week that improved relations are necessary between the countries to encourage the continued exchange of students. Chinese officials have indicated that the future of the Fulbright Scholar exchange programmes, which sponsors Chinese students in the United States, might depend on Bush's veto of the congressional bill. China halted the Fulbright programme in retaliation for sanctions imposed after the Beijing riots last summer.

There are 40,000 Chinese students in the United States, of which 32,000 hold visas requiring them to return to China before renewing or changing their status. Students holding such a visa, known as a ' $\mathrm{J}-1$ ', must return to their country for at least two years before reapplying. The congressional bill would have given Chinese students up to four more years to apply for new visas or for permanent residence without returning to China.

Seven thousand students have been allowed into the United States since the Tiananmen Square massacre last June. Since the demonstrations, application to study in the US have risen more than 60 per cent. But more than half of those applying are rejected by the US Embassy because they cannot prove that they are well qualified for the programmes they have chosen, that they will be able to support themselves, or that they will return when their studies are over.

Most of the students and workers who participated in the June demonstrations are still at large, a situation the Chinese government is said to find embarrassing. Nevertheless, thousands of others have been arrested. At least 40 protesters have been executed since June, according to Asia Watch, a human-rights organization. Although most of those brought to trial have so far been workers and unemployed, Asia Watch reports that authorities have recently begun conducting secret trials of students as well.

G. Christopher Anderson Threat from UK reforms

\section{London}

THE British government's plans to reform the National Health Service (NHS) are coming under fire from the some of main bodies supporting medical research, for failing to account for the needs of clinical research.

The bill, now being discussed by a House of Commons committee, aims to create a competitive 'internal market' within the NHS so that patients will be referred to hospitals that offer the cheapest treatment. The problem is that clinical research inevitably involves increased treatment costs. Sir Walter Bodmer, director of research for the Imperial Cancer Research Fund (ICRF), fears that, without additional government money to support these 'service costs', hospitals may be forced to cut back their clinical research programmes.

The government has accepted that some additional support for research is needed, but Bodmer describes their proposals to achieve this as "totally inadequate". The Department of Health intends to increase the money distributed to hospitals for teaching-related costs, the Service Increment for Teaching (SIFT), by about two per cent in real terms, to cover research service costs. But this money is allocated to hospitals on the basis of undergraduate medical and dental student numbers, which bear little relation to clinical research activity.

The idea to extend SIFT comes from a steering group chaired by Sir Christopher France, permanent secretary at the Department of Health. Opponents point out that the group's remit was extended from planning undergraduate teaching to considering research shortly after the government's plans for the NHS were outlined, but the research community was never asked to take part.

ICRF proposes that instead of an increased SIFT, a new Service Increment for Research (SIFOR) should be targeted specifically to benefit those hospitals running clinical research programmes.

ICRF's proposals are supported by the Cancer Research Campaign. These two charities already divert about a third of their budgets for many hospitals into basic patient care, much more than most medical charities, and fear that the NHS bill will exacerbate the situation.

But other organizations believe that ICRF's proposals are not immediately practical. Diana Garnham, of the Association of Medical Research Charities (AMRC), explains that the data to implement SIFOR schemes are not yet available. Clinical research in the NHS is funded from a wide variety of sources and there has been no attempt to document the total level of research activity in different hospitals. AMRC would like to see something along the lines of SIFOR as a long-term goal, but a more realistic short-term approach is to suggest how the Department of Health could get an indication of where clinical research is centred, so that the distribution of SIFT could be modified accordingly.

The Medical Research Council (MRC) holds similar views. Present arrangements for the distribution of SIFT will be reviewed in 1992, and the MRC accepts that no major changes are likely before then.

Opposition to the NHS bill is also coming from the universities, which run hospital medical and dental schools. The Committee of Vice-Chancellors and Principals (CVCP) is unhappy with the proposed level of university representation in the local management of the NHS.

Peter Aldhous 